komplexen und »ptolemäischer« Weltdeutung dürften dies bezeugen. Man tut Benns Prosa, vor allem seine Essays, oft vorschnell als hermetische Ausdrucksversuche $a b$, die sich, wie man meint, einer begrifflichen Aufschlüsselung entziehen. In Wirklichkeit sind sie rationale Gebäude aus metaphorischen Bausteinen. Letztere muß man im einzelnen durchschaut und nach Struktur wie Funktion bestimmt haben, um sich einem Verständnis des Ganzen annähern zu können. Hilfreich dürfte die Einsicht werden, daß sich Hauptlinien von Benns Werk wegen ihres gemeinsamen Knotenpunktes in der gehirntopologischen Vorstellungssphäre zu einem Denkmodell verdichten, wie es in dieser Geschlossenheit und Prägekraft nicht leicht bei einem anderen Autor auffindbar sein wird.

('Studien zu Gottfried Benn II’ folgen')

\title{
Heimito von Doderer-Briefe gesucht
}

Alle Besitzer noch nicht gedruckter Briefe von Heimito von Doderer werden gebeten, sich mit der Östereichischen Gesellschaft für Literatur, Herrengasse 5, A-roıo Wien, in Verbindung zu setzen. Die Kenntnis dieser Briefe wird für die Erstellung eines Verzeichnisses des gesamten Nachlasses Heimito von Doderers benötigt. Die Österreichische Gesellschaft für Literatur bittet die Besitzer um Fotokopien der Briefe gegen Ersatz der Kosten. 